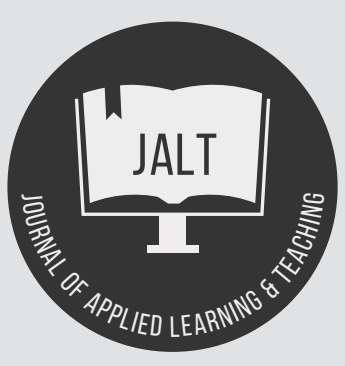

Vol.1 No.1 (2018)

Journal of Applied Learning \& Teaching

Content Available at : http://journals.sfu.ca/jalt/index.php/jalt/index

\title{
Sam C. Y. (2017). Private education in Singapore. Contemporary issues and challenges. Singapore: World Scientific.
}

DOI: https://doi.org/10.37074/jalt.2018.1.1.7

\section{Stevphen Shukaitis}

Senior Lecturer, Centre for Work, Organisation and Society, University of Essex

Like many academics, I'm not very good at small talk, whether at department events or social engagements. Once outside the comfort of one's area of specialism, things can quickly become awkward (which is the UK's default emotional setting), collapsing into pleasantries or complaints about the weather. Maybe it's not all that surprising one of the first questions asked upon meeting someone is 'what do you do?' which is always taken as a question about one's wage labouring status, or within an academic setting, your research area. How can you be placed? In those conversations sooner or later I end up mentioning working on a university programme in partnership with Kaplan Singapore. The responses to that are interesting; they often bring up widely varying assumptions both about Singapore and private education.

At present there are over 300 private education institutions (PEls) in Singapore involving over 150,000 students. This is significantly more than enrolled in public universities, in a country whose population is only around 5.6 million. Despite this, very little is written about the nature of private education in Singapore. This is where a book like Sam Choon-Yin's Private Education in Singapore is valuable. It would have been helpful if someone had handed a copy to me upon when I took up a role working on Essex's partnership with Kaplan. At least it would have supplied me with some more convincing things to say when faced with questions about the programme. While no copy was presented then, I was fortunate enough to stumble across it while perusing through a bookstore during a visit to Singapore.

Sam Choon-Yin is well placed for writing a book such as this. He is currently the Dean at the PSB Academy and has worked in private education for more than two decades. The book is framed as an attempt to sketch an overall picture of the industry rather than give a deep history of any particular institution. This is a perfectly reasonable approach, though at times it does seem to be perhaps a bit overly schematic, replicating information about entry standards and programme information that is presumably taken off from the relevant websites. And one might wonder if Sam's position as Dean might make him very careful about his words, more wanting to say things that will reflect upon his institution and the sector than anything else. That would be a fair question, though he does not single out any particular institution for criticism. And it would be perfectly reasonable enough for you, Dear Reader, to ask similar questions about this review, or the journal itself. Does it embody a genuine academic engagement with the subject or is it marketing puff? Only time will tell, but l'd suggest starting from giving this book, as well as the journal, the benefit of the doubt.

One of the book's main thrusts is addressing what is described as the dominant attitude towards private education in Singapore, namely that it is "low in quality and scandal-prone" (xv). These scandals have ranged from PEls offering degrees not properly accredited to the closing or failure of programmes, or more generally to a lack of sufficient attention to standards and quality. Perhaps this is not so surprising given how recent decades have seen an immense expansion in private education in Singapore, leading to an "uneven quality of provisions across the sector" (37). Sam addresses these concerns at multiple points through the book, suggesting that it is often the unethical actions of a few giving a bad impression to the overall industry. He also suggests that this can be better addressed through better corporate governance.

It is these negative forms of attention on private education in Singapore that led to the formation of new regulatory bodies, such as the Council of Private Education, or CPE, which has now changed its name to the Committee for Private Education. According to Sam, the creation of the $\mathrm{CPE}$ and its actions have "restored some confidence in the private education sector" (42). These are the kinds of questions, sans details, that I often find myself being asked at the awkward social and workplace encounters this review began with. Why do people choose to enrol in a degree programme with a private education provider, regardless of whether or not it is partnered with a reputable sounding university? The assumption often lurking in such 
questions is that the nature of private education is to act in a predatory manner in relationship with public institutions.

Putting aside the question in a broader sense, at least it seems clear that this is not the case in the Singaporean context. Rather through how the government has restricted the number of places available in the public universities, attempting to maintain very high standards and thus maximizing international league table rankings. This is an approach that thus far has played out well for public universities in Singapore. But this has also meant that there are far greater demands for university education than there are spaces available within the public universities. And that remains the case despite the creation of a few universities, such as the Singapore University of Technology and Design and the Singapore Institute of Technology. Read charitably then one could come to the impression that private education takes up the role of expanding and extending opportunity to populations and students who otherwise it would not be available to. Has it become the role of private education to pick up what the Singaporean state does not do? How do the changing demographics and evolving politics change the role of private education in Singapore?

This is where Sam's book is the most useful, charting out the various institutional and industry-wide trends. While he might prefer to only say positive things about the people he has worked with that does not stop him from being honest about the challenges faced by PEls, ranging from international students with a weaker grasp of English and lower motivation to study (which is an issue that is far from being confined to Singapore) to the almost exclusive use of sessional or part-time teaching staff who "may treat teaching as merely contractual arrangement, devoting their time and energy only during contracted hours" (131). I found that a perplexing suggestion, which gets repeated at least twice. If someone is hired on a teaching-only contract, why would they treat it as something other than a contractual relationship? Is it reasonable to expect a deep-seated vocational attachment to one's teaching work when there is little guarantee of continued job security? How could one expect to build strong or committed academic cultures when everyone is employed module by module?

Sam does not speculate much on the future of higher education in Singapore. This strikes me as wise given that, as the joke goes, social scientists have enough trouble predicting the past, let alone the future. He does note how demographic shifts and the changing focus of the CPE to issues of academic excellence could lead to greater centralization of PEls as larger institutions absorb or acquire smaller ones. Likewise the rise in available places in public universities will make it more difficult for PEls to attract more students (84). And in that sense, this is a very useful book, giving an overall impression of the industry but without being too prescriptive. If I should happen to meet Sam Choon-Yin, and manage to get past the stage of awkward small talk, I might challenge him on his overall conception of education, as he describes the "essential idea of education is to produce students who are industry ready" (156). Education to me has always seemed to be, or should be, more geared to facilitating of human flourishing, of cultivating skills and dispositions that may indeed be useful in the workplace, but also far beyond it. But that's a much broader conversation to be had after the awkward small talk, and one that can only be had once one has gotten a good understanding of the overall field. In Private Education in Singapore, Sam Choon-Yin does an admirable job getting us there.

Copyright: ( 2020 Stevphen Shukaitis. This is an open-access article distributed under the terms of the Creative Commons Attribution License (CC BY). The use, distribution or reproduction in other forums is permitted, provided the original author(s) and the copyright owner(s) are credited and that the original publication in this journal is cited, in accordance with accepted academic practice. No use, distribution or reproduction is permitted which does not comply with these terms. 